\title{
In vivo confirmation of altered hepatic glucose metabolism in patients with liver fibrosis/cirrhosis by ${ }^{18} \mathrm{~F}$-FDG PET/CT
}

\author{
Niklas Verloh ${ }^{1,2^{*}+} \mathbb{D}$, Ingo Einspieler ${ }^{2+}$, Kirsten Utpatel ${ }^{3}$, Karin Menhart ${ }^{1}$, Stefan Brunner ${ }^{4}$, Frank Hofheinz ${ }^{5}$, \\ Jörg van den Hoff5, Philipp Wiggermann ${ }^{2,6}$, Matthias Evert ${ }^{3}$, Christian Stroszczynski ${ }^{2}$, Dirk Hellwig ${ }^{1}$ \\ and Jirka Grosse ${ }^{1}$
}

\begin{abstract}
Objective: The aim of this study was to assess the value of ${ }^{18} \mathrm{~F}$-FDG PET/CT for quantitative assessment of hepatic metabolism in patients with different stages of liver fibrosis/cirrhosis.

Materials and methods: ${ }^{18} \mathrm{~F}-\mathrm{FDG}$ PET/CT scans of 37 patients either with or without liver fibrosis/cirrhosis, classified according to the METAVIR score (F0-F4) obtained from histopathological analysis of liver specimen, were analyzed retrospectively and classified as follows: no liver fibrosis ( $F 0, n=6)$, mild liver fibrosis ( $F 1, n=11)$, advanced liver fibrosis $(F 2, n=6)$, severe liver fibrosis $(F 3, n=5)$, and liver cirrhosis $(F 4, n=11)$. The liver-to-blood ratio (LBR, scan time corrected for a reference time of $75 \mathrm{~min}$ ) was compared between patient groups.

Results: Patients with liver fibrosis or cirrhosis ( $\geq$ F1; LBR $1.53 \pm 0.35$ ) showed a significant higher LBR than patients with normal liver parenchyma (FO, $1.08 \pm 0.23 ; P=0.004)$. In direct comparison, LBR increased up to the advanced stage of liver fibrosis ( $F 2 ; 2.00 \pm 0.40)$ and decreased until liver cirrhosis is reached (F4, 1.32 \pm 0.14$)$.

Conclusion: Functional changes in liver parenchyma during liver fibrosis/cirrhosis affect hepatic glucose metabolism and significantly differ between stages of liver fibrosis/cirrhosis, classified according to the METAVIR scoring system, as demonstrated by LBR quantification by ${ }^{18} \mathrm{~F}-\mathrm{FDG}$ PET/CT.
\end{abstract}

Keywords: ${ }^{18}$ F-FDG PET/CT, Hepatic metabolism, Liver fibrosis, Liver cirrhosis, FDG kinetics, METAVIR score

\section{Introduction}

The increasing prevalence of chronic liver diseases is a growing problem for the Western Hemisphere, as patients' morbidity and mortality are directly correlated with the progression of hepatic fibrosis. Today, liver cirrhosis is among the leading causes of mortality in the Western Hemisphere and causes significant health care costs $[1-4]$.

Various imaging modalities, including computed tomography (CT), magnetic resonance imaging (MRI), and ultrasonography (US), are being used to evaluate

\footnotetext{
* Correspondence: niklas.verloh@ukr.de

${ }^{+}$Niklas Verloh and Ingo Einspieler contributed equally to this work.

'Department of Nuclear Medicine, University Hospital Regensburg,

Regensburg, Germany

2Department of Radiology, University Hospital Regensburg, Regensburg, Germany

Full list of author information is available at the end of the article
}

the liver parenchyma [5-9]. In conventional nuclear medicine, scintigraphy and single-photon emission computed tomography with ${ }^{99 \mathrm{~m}}$ Tc-IDA or ${ }^{99 \mathrm{~m}} \mathrm{Tc}-\mathrm{GSA}$ can be used to quantify hepatic function and assess liver fibrosis and hepatic functional reserve [10-14]. Apart from that, technically more complex positron emission tomography (PET) is an emerging imaging modality with superior spatial resolution, which is used not only in oncology but increasingly also to visualize infectious, inflammatory, and degenerative diseases $[15,16] .{ }^{18}$ F-fluoro-2-deoxy-D-glucose (FDG) is the most commonly used radiopharmaceutical for PET examinations. It allows the quantification of glucose metabolism in different tissues.

The quantification of regional glucose metabolism can be achieved by kinetic analysis of FDG uptake of dynamic PET acquisitions or more simply by means of 
standardized uptake value (SUV) measurements from static PET images $[15,17]$. However, the accuracy and reproducibility of the SUV for quantitative analysis of whole-body PET/CT examinations are influenced by both technical and biological factors, leading to a limited test-retest reproducibility of SUV measurements [18]. The tissue-to-blood ratio (TBR) specifies the ratio between an organ and the (aortic) blood pool and is insensitive to cross-calibration errors between PET scanners and dose calibrators [18]. However-like SUV-it does not take into account the biology-driven time dependence of the FDG accumulation, which contributes substantially to incongruent results with respect to comparative studies. For tumors, the tumor-to-blood standard uptake ratio (SUR) was introduced to overcome both technical and biological factors, potentially leading to a more accurate quantification of FDG uptake and thus of glucose metabolism [19]. For tissue analysis, the correction of SUV for the scan time interval results in improved comparability of PET examinations acquired at different times after FDG injection [20]. The correction used for SUR calculations is based mainly on the observations that, on the one hand, the FDG concentration in arterial blood exhibits a hyperbolic decline pattern, and on the other hand, the tumor-to-blood ratio over time becomes almost linear after tracer equilibration in the blood. Unlike with malignant tumors, the uptake of FDG into the liver does not follow an irreversible kinetics. It exhibits a low and homogeneous uptake of ${ }^{18} \mathrm{~F}$-FDG into the liver parenchyma [21-24].

To what extent FDG uptake is affected by diffuse liver diseases is not clear yet. Hernandez-Martinez et al. reported that the FDG uptake was reduced in cirrhotic livers (defined by anatomical imaging criteria) compared to the control group [25]. Some studies, evaluating the ${ }^{18}$ F-FDG uptake in liver steatosis, reported an increasing SUV compared to normal liver parenchyma, whereas others observed no such difference [26-28]. In addition, there is evidence that a higher hepatic glucose metabolism with higher ${ }^{18} \mathrm{~F}$-FDG uptake into the liver parenchyma is associated with increased expression of GLUT-1 and hexokinase II $[29,30]$.

For assessing liver inflammation in non-alcoholic steatohepatitis (NASH), a recent study showed that the dynamic ${ }^{18}$ F-FDG-PET with kinetic modeling has the potential to assess liver inflammation in patients with $\mathrm{NASH}$, while hepatic glucose metabolism assessed by means of SUV-analyzes gave no promising results [31].

The precise assessment of hepatic ${ }^{18} \mathrm{~F}$-FDG accumulation and distribution could be essential, considering the unmet need for noninvasive staging of chronic liver diseases. Given the potential role of molecular imaging in the assessment of hepatic disorders, the aim of this study was to evaluate hepatic glucose metabolism in patients with different stages of liver fibrosis/cirrhosis by means of ${ }^{18} \mathrm{~F}$-FDG PET/CT.

\section{Materials and methods}

\section{Patients}

We retrospectively analyzed 37 consecutive ${ }^{18}$ F-FDG $\mathrm{PET} / \mathrm{CT}$ scans and corresponding histopathological liver samples obtained between 11/2008 and 09/2017.

${ }^{18} \mathrm{~F}$-FDG PET/CT was performed for staging and follow-up of malignant diseases, whereas biopsy of the liver was done due to known liver fibrosis/cirrhosis or suspicious liver lesion. Patients were included if the timespan between ${ }^{18} \mathrm{~F}$-FDG PET/CT and histopathological examination did not exceed 6 months. Patients treated with chemotherapy or radiation therapy during the 6 months prior to FDG-PET/CT imaging were excluded. Patient characteristics are shown in Table 1.

Approval from the local ethics committee of the University Hospital Regensburg was obtained, and this retrospective study was performed in accordance with all relevant guidelines and regulations.

\section{Imaging}

${ }^{18}$ F-FDG PET/CT imaging was performed using a Biograph $16 \mathrm{PET} / \mathrm{CT}$ scanner (CTI-Siemens, Erlangen, Germany) consisting of a 16-slice multidetector CT ( $0.5 \mathrm{~s}$ per revolution) and a PET detector with an axial and transaxial field-of-view of $162 \mathrm{~mm}$ and $585 \mathrm{~mm}$, respectively.

After a fasting period of at least $6 \mathrm{~h}, 3 \mathrm{MBq}{ }^{18} \mathrm{~F}$-FDG per kilogram body weight were injected intravenously $(321 \pm 48 \mathrm{MBq})$. The patients' blood glucose level was strictly controlled to be below $150 \mathrm{mg} / \mathrm{dL}(8.32 \mathrm{mmol} /$ L). To increase renal tracer elimination, they received an injection of $20 \mathrm{mg}$ furosemide as well as oral or intravenous hydration shortly after ${ }^{18} \mathrm{~F}$-FDG injection. In order to minimize muscular ${ }^{18} \mathrm{~F}$-FDG uptake, patients were advised to stay in a quiet lying position. Warming blankets were used to avoid freezing of the patients and to keep potential tracer accumulation in brown fat tissue to a minimum. Patients were

Table 1 Patients characteristics. Continuous measures are reported as mean with the corresponding standard deviation.

\begin{tabular}{ll}
\hline Male $[n(\%)]$ & $22(60)$ \\
Age [years] & $61 \pm 13$ \\
Height $[\mathrm{m}]$ & $1.71 \pm 0.07$ \\
Weight $[\mathrm{kg}]$ & $81 \pm 18$ \\
BMl $\left[\mathrm{kg} / \mathrm{m}^{2}\right]$ & $27.5 \pm 6.2$ \\
Blood glucose level $[\mathrm{mg} / \mathrm{dl}]$ & $112 \pm 25$
\end{tabular}

$B M I$ body mass index 
instructed to void the bladder prior to scanning and to remove all metal parts.

After a waiting period of about $60 \mathrm{~min}$ post-injection (minimum $50 \mathrm{~min}$, maximum $90 \mathrm{~min}$ ), the $\mathrm{PET} / \mathrm{CT}$ acquisition was performed with elevated arms to acquire images of the trunk (pelvis to skull base). Depending on the patient size and clinical indication, six to eight overlapping bed positions with $3 \mathrm{~min}$ of PET acquisition time each were used. The same area was covered by a low-dose CT scan (tube current $50 \mathrm{mAs}$, tube voltage $120 \mathrm{keV}$ ) if no contrast agents were used. In 17 patients, intravenous contrast agent $(130 \mathrm{ml}$ of Accupaque $^{\mathrm{Tu}} 300$, GE Healthcare) was applied with consecutive full-dose CT acquisition (120 keV, $100 \mathrm{mAs}$ ).

PET images (slice thickness $5 \mathrm{~mm}$ ) were corrected for random coincidences, decay, scatter, and attenuation and reconstructed iteratively using the ordered subsets expectation maximization algorithm (OSEM) with four iterations and eight subsets. PET images were scaled to allow SUV measurements. PET and CT images were checked for breathing artifacts.

\section{Image analysis}

Images were interpreted by a nuclear medicine physician and a radiologist. To determine the $\mathrm{SUV}_{\text {mean }}$ in the liver parenchyma, a 3D volume of interest (VOI) was placed manually in the right liver lobe, excluding visible vessels and liver lesions. VOI size ranged from 13.6 to $17.2 \mathrm{~cm}^{3}$. To control for the potential interindividual differences in overall glucose metabolism, VOIs with a diameter of $1 \mathrm{~cm}$ were placed in the gluteal muscle to determine the $\mathrm{SUV}_{\text {mean }}$. The aortic blood pool SUV was determined by delineating the aorta in the attenuation $\mathrm{CT}$. The resulting intraluminal ROI was then transferred to the coregistered PET image and the mean value was set as the blood pool value. Tissue-to-blood ratios (TBR, Eq. 1) and the time corrected liver-to-blood ratio (LBR, Eq. 2) were calculated using the following formulas:

$$
\begin{aligned}
& \text { Tissue-to-blood ratio }(T)(\mathrm{TBR}) \\
& =\frac{\mathrm{SUV}(T) \text { mean }_{\text {Target }}}{\operatorname{SUV}(T) \text { mean }_{\text {Blood pool }}}
\end{aligned}
$$

$$
\begin{aligned}
& \text { Liver-to-blood ratio }\left(T, T_{0}\right)(\mathrm{LBR}) \\
& =\left(\frac{T_{0}}{T}\right)^{b} \times \frac{\operatorname{SUV}(T) \text { mean }_{\text {Target }}}{\operatorname{SUV}(T) \text { mean }_{\text {Blood pool }}} \\
& =\left(\frac{T_{0}}{T}\right)^{b} \times \operatorname{TBR}(T),
\end{aligned}
$$

with $T_{0}$ : reference time (75 $\left.\mathrm{min}\right), T$ : acquisition time, and $b$ : correction factor (set to 0.313 according to [20]).

\section{Histopathological examination}

For the histopathological examination, liver biopsies or partial resections were used. The length of each biopsy specimen was measured, and the number of portal tracts was assessed. The liver samples were included in the evaluations only when the tissue length exceeded $15 \mathrm{~mm}$ and more than ten portal tracts were visible. Only non-tumorous liver tissue was included in this study. All samples were fixed in formalin and embedded in paraffin. Four-micrometer sections were cut vertically and mounted on glass slides. The sections were deparaffinized with xylene and ethanol and stained with hematoxylin-eosin (HE) and Elastica van Gieson (EVG) according to standard protocols. EVG staining was used to evaluate the liver fibrosis with collagen stained red and hepatocytes stained yellow.

Two pathologists (M.E. and K.U.), who specialize in liver histopathology, assessed/evaluated/graded the samples' degrees of fibrosis/cirrhosis using the METAVIR scoring system $[32,33]$. Both readers were blinded to the imaging results and the patient data. The scoring was performed independently. In cases of disagreement, additional microscopic analyses were performed and a common final judgment was made in consensus. The patients were subdivided into the following five categories: F0 $(n=6)$ no fibrosis, F1 $(n=11)$ mild fibrosis, F2 $(n=6)$ advanced fibrosis, F3 $(n=6)$ severe fibrosis, and F4 $(n=11)$ cirrhosis.

\section{Statistical analysis}

All statistical analyses were performed with IBM SPSS Statistics (version 24, Chicago, IL, USA). The data are presented as mean \pm standard deviation (SD). Non-parametric Mann-Whitney $U$ test for independent variables were used to compare groups. All tests were two-sided and a significance level of $p<0.05$ was considered significant.

\section{Results}

Patients with liver fibrosis/cirrhosis $\left(\geq \mathrm{F} 1 ; \mathrm{SUV}_{\text {Liver }}\right.$ $2.48 \pm 0.32$ ) showed a significantly higher SUV of the liver parenchyma (SUV 2.48+-0.32) than patients with normal liver parenchyma (F0; $\mathrm{SUV}_{\text {Liver }} 1.76 \pm$ $0.31 ; p<0.001$ ), while the SUV of the skeletal muscle did not differ between the groups (Table 2). Figure 1 shows the SUVs of the liver parenchyma, aortic blood pool, and skeletal muscle in patients with liver fibrosis/ cirrhosis and patients with normal liver parenchyma.

In the non-time-corrected TBR analysis, a comparison between patients with and without liver fibrosis/ cirrhosis as stratified according to the METAVIR scoring system revealed that $\mathrm{TBR}_{\text {Liver }}$ increased up to advanced liver fibrosis $\left(\mathrm{F} 2\right.$; $\left.\mathrm{TBR}_{\text {Liver }} 1.93 \pm 0.40\right)$ and then decreased until liver cirrhosis is reached (Table 2). Compared to the altered glucose metabolism of the 
Table 2 This table shows the mean standardized uptake values (SUV) of the liver parenchyma, aortic blood pool, and skeletal muscle with their corresponding tissue-to-blood ratios (TBR), as well as the time corrected liver-to-blood-ratio (LBR) for patients with normal liver parenchyma and patients with different stages of liver fibrosis according to the METAVIR classification

\begin{tabular}{|c|c|c|c|c|c|c|}
\hline & Mean SUV blood & Mean SUV liver & Mean SUV muscle & TBR Liver $_{\text {Lin }}$ & $\mathrm{TBR}_{\text {Muscle }}$ & LBR \\
\hline $\begin{array}{l}\text { No liver fibrosis } \\
(F 0, n=6)\end{array}$ & $1.72 \pm 0.23$ & $1.76 \pm 0.31$ & $0.77 \pm 0.20$ & $1.04 \pm 0.23$ & $0.44 \pm 0.08$ & $1.08 \pm 0.23$ \\
\hline $\begin{array}{l}\text { Mild liver fibrosis } \\
(F 1, n=11)\end{array}$ & $1.75 \pm 0.31$ & $2.31 \pm 0.31$ & $0.74 \pm 0.25$ & $1.35 \pm 0.25$ & $0.42 \pm 0.16$ & $1.44 \pm 0.27$ \\
\hline $\begin{array}{l}\text { Advanced liver fibrosis } \\
(F 2, n=6)\end{array}$ & $1.45 \pm 0.46$ & $2.64 \pm 0.36$ & $0.58 \pm 0.07$ & $1.93 \pm 0.40$ & $0.43 \pm 0.09$ & $2.00 \pm 0.40$ \\
\hline $\begin{array}{l}\text { Severe liver fibrosis } \\
(F 3, n=5)\end{array}$ & $1.75 \pm 0.33$ & $2.62 \pm 0.29$ & $0.72 \pm 0.18$ & $1.55 \pm 0.23$ & $0.41 \pm 0.06$ & $1.53 \pm 0.20$ \\
\hline $\begin{array}{l}\text { Liver cirrhosis } \\
(F 4, n=11)\end{array}$ & $1.90 \pm 0.22$ & $2.49 \pm 0.24$ & $0.68 \pm 0.10$ & $1.32 \pm 0.15$ & $0.36 \pm 0.05$ & $1.32 \pm 0.14$ \\
\hline
\end{tabular}

liver parenchyma, no significant difference of TBR for the skeletal muscle was found. Figure 2 shows the boxplots of the ratio between the mean SUV in the liver tissue $\left(\mathrm{TBR}_{\text {Liver }}\right)$ and in the skeletal muscle $\left(\mathrm{TBR}_{\mathrm{Mus}}\right.$ cle), corrected with the aortic blood pool, in patients with normal liver parenchyma and patients with liver fibrosis/cirrhosis and the corresponding significance values for the analyzed patients.

Patients with liver fibrosis/cirrhosis ( $\geq$ F1) showed a significantly higher LBR $(1.53 \pm 0.35)$ than patients with normal liver parenchyma (F0; $1.08 \pm 0.23 ; p=0.004$ ). In pairwise comparison, significant differences in LBR were observed between patients without fibrosis (F0) and those with mild liver fibrosis (F1; LBR $1.44 \pm$ $0.27 ; p=0.035$ ) and between patients with initial and those with advanced liver fibrosis (F2; LBR $2.00 \pm$ $0.40 ; p=0.015)$. A significant difference was observed between the patients with advanced and severe liver fibrosis (F3; LBR $1.53 \pm 0.20 ; p=0.028$ ). No significant difference was observed between patients with severe liver fibrosis and liver cirrhosis (F4; LBR $1.32 \pm 0.14$; $p=0.053$ ). However, a $p$ value of 0.053 indicates a trend towards significance.

Figure 3 and Table 3 show the boxplots and the corresponding significance values for the analyzed patients.

\section{Discussion}

Liver cirrhosis is characterized by nodular regeneration of liver tissue with the destruction of the lobular and vascular architecture [34-36]. The progression of liver fibrosis and the development of liver cirrhosis are currently viewed as a dynamic process [37]. In the development of inflammation and fibrosis, different factors such as oxidative stress, mitochondrial changes, and hormonal disorders are taken into account as factors [38-40]. With increased tissue remodeling during wound healing processes, one can assume higher glucose metabolism in the liver parenchyma.

We observed that the TBR and the LBR of the liver increase with advanced liver fibrosis (F1 to F2). In patients with severe liver fibrosis (F3) or liver cirrhosis (F4), the LBR then decreases compared to patients with advanced liver fibrosis, indicating a higher activity level of tissue remodeling in patients with advanced liver fibrosis (Fig. 4). These findings are in accord with the morphological changes in the expression of GLUT in the liver parenchyma because hepatocytes are capable of gluconeogenesis and their need for glucose uptake is modest [41]. In normal liver parenchyma, all GLUTs are expressed, except for GLUT-7 [42], and the liver parenchyma shows overexpression of GLUT-2, -8 ,
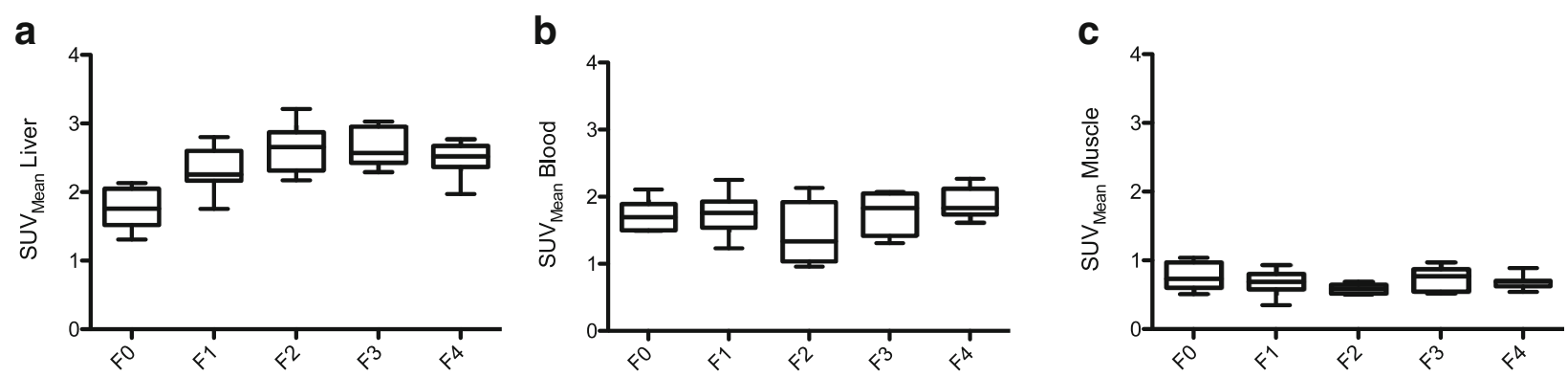

Fig. 1 The standardized uptake values (SUV) of the liver parenchyma (a), the aortic blood pool (b), and the skeletal muscle (c) in patients with normal liver parenchyma and patients with liver fibrosis/cirrhosis are shown. The Mann-Whitney $U$ test was used to compare the following groups: no (F0), mild (F1), advanced (F2), severe liver fibrosis (F3), and liver cirrhosis (F4) 

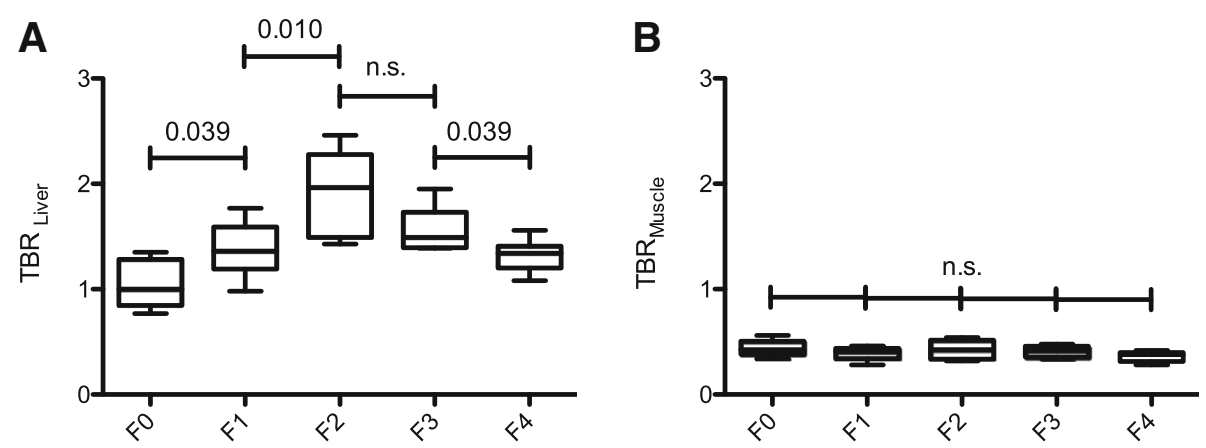

Fig. 2 Shows the tissue-to-blood ratios (TBRLiver, (a); TBRMuscle, (b)) in patients with normal liver parenchyma and patients with liver fibrosis/cirrhosis. The Mann-Whitney $U$ tests was used to compare the groups: no (F0), mild (F1), advanced (F2), severe liver fibrosis (F3), and liver cirrhosis (F4)

-9 , and -10 [43]. GLUT-1 and GLUT-2 allow for efficient uptake of glucose at low plasma glucose concentrations [44]. Expression of these transporters in liver cells is restricted to hepatocytes proximal to the hepatic venule [45]. In damaged liver parenchyma, the majority of GLUTs are upregulated compared to normal liver parenchyma [43] and the expression of GLUT-1 in hepatocytes is increased, while GLUT-2 is decreased [46]. While GLUT-2 ensures, independently of insulin, with its low affinity and high transport capacity, that intracellular and extracellular glucose concentrations are in equilibrium [47], GLUT-1 has a higher affinity for glucose and is nearly saturated under physiological conditions [48]. In addition, the amine oxidase activity of VAP-1 is upregulated in chronic liver diseases [49]. VAP-1 plays a significant role in glucose uptake into hepatocytes as it stimulates glucose uptake via translocation of transporters to the cell membrane $[43,50]$. In conclusion, the high affinity of GLUT-1 for glucose in combination with its

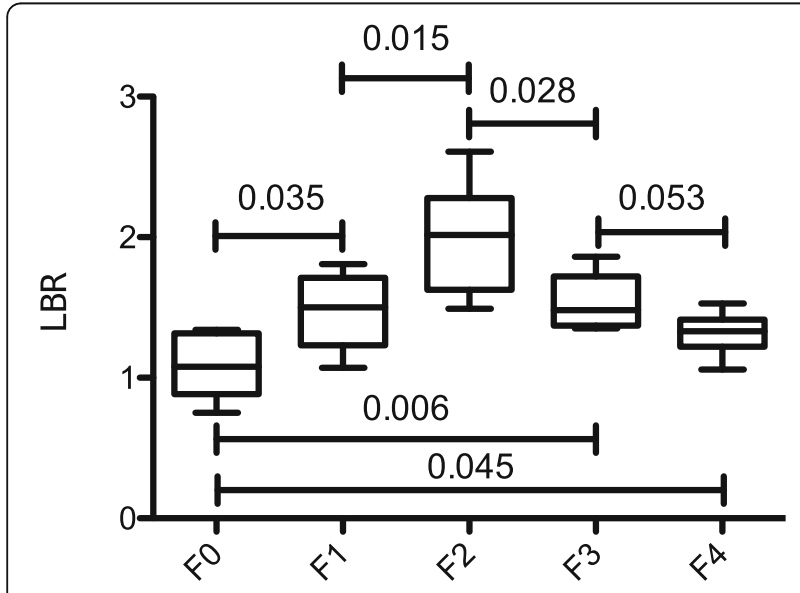

Fig. 3 LBR in patients with normal liver parenchyma and patients with liver fibrosis/cirrhosis. Mann-Whitney $U$ tests were used to compare the groups: no (F0), mild (F1), advanced (F2), severe liver fibrosis (F3), and liver cirrhosis (F4) increased expression in damaged liver parenchyma might explain the increased ${ }^{18} \mathrm{~F}$-FDG uptake we observed in patients with liver fibrosis suggesting a higher glucose uptake for liver cells.

Non-parenchymal liver cells, which cannot carry out gluconeogenesis, rely on glucose uptake rather than on endogenous formation. GLUT-1 is the dominant transporter protein in both endothelial cells and Kupffer cells, and its expression levels increase during inflammation induced by lipopolysaccharide [51].

In the process of tissue remodeling in liver parenchyma, inflammation plays an important role [52-54]. As a reaction to damaged hepatocytes, apoptotic bodies will be recruited to interact with quiescent hepatic stellate cells and Kupffer cells to activate and promote inflammatory and fibrogenic responses $[55,56]$. As a consequence, the enhanced inflammatory and immune-mediated responses will promote hepatocyte necrosis and apoptosis, which nurtures further fibrogenic processes [57].

One may argue that Kupffer cells are more dominant in patients with higher levels of active tissue remodeling, as it is observed for patients with advanced liver fibrosis (F2). This might explain the increased glucose metabolism in patients with advanced liver fibrosis in addition to elevated ${ }^{18} \mathrm{~F}$-FDG uptake in damaged hepatocytes as described above.

In our study, patients with severe liver fibrosis (F3) or liver cirrhosis (F4) showed a decreased glucose

Table 3 Differentiation between the stages of liver fibrosis

\begin{tabular}{llllll}
\hline & F0 & F1 & F2 & F3 & F4 \\
\hline F0 & & 0.035 & 0.002 & 0.006 & 0.045 \\
F1 & 0.035 & & 0.015 & 0.571 & 0.362 \\
F2 & 0.002 & 0.015 & & 0,028 & 0.001 \\
F3 & 0.006 & 0.571 & 0.028 & & 0.053 \\
F4 & 0.045 & 0.362 & 0.001 & 0.053 & \\
\hline
\end{tabular}

Comparison of the different stages of liver fibrosis, stratified by the METAVIR scoring system, with the corresponding $p$ values: no (F0), mild (F1), advanced (F2), severe liver fibrosis (F3), and liver cirrhosis (F4) 

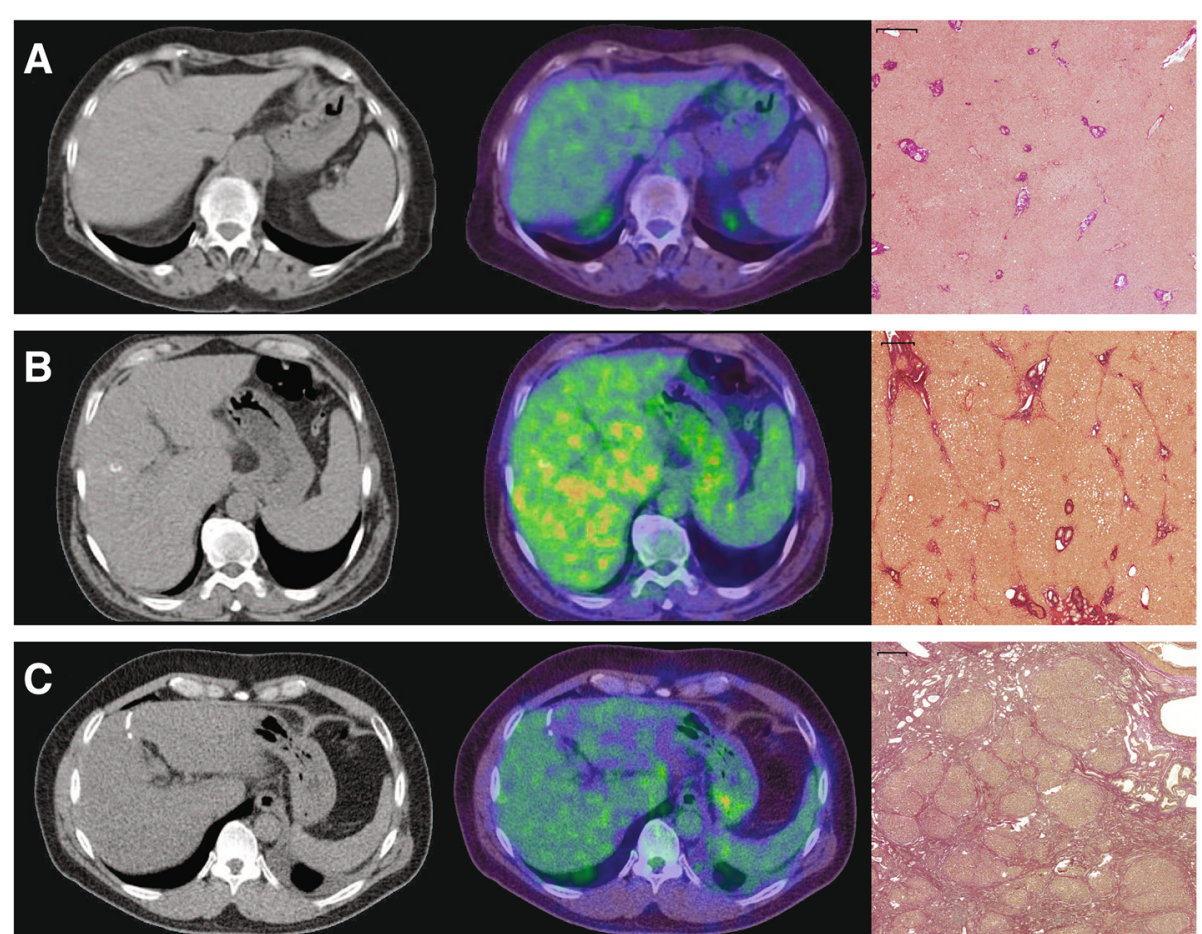

Fig. 4 CT- (left column) and fused PET/CT-images (middle column) of patients with normal liver parenchyma (a), advanced liver fibrosis (b), and with liver cirrhosis (c) with the corresponding histopathology images demonstrating EVG staining (right column). CT images are displayed with the same window (400) and center (40) level. The fused PET/CT-images are shown with an upper SUV threshold of 7.0 using the spectrum color lookup table (SyngoVia) for PET. The scale on histological slices represents $500 \mu \mathrm{m}$

metabolism compared to patients with advanced liver fibrosis (F2), while maintaining a higher glucose metabolism than patients with normal liver parenchyma (F0) (Fig. 3). These results are in contrast to HernandezMartinez et al., who reported a reduced FDG uptake in cirrhotic livers in comparison to the control group [25]. However, Hernandez-Martinez et al. [25] used a combination of clinical, histopathological, and imaging data for the classification of liver disease, whereas we used a validated histopathological scoring system, the METAVIR scoring system. Furthermore, they used the error-prone SUV measurements, in contrast to our scan time corrected LBR quantification.

There are some potential biological explanations for our observations. The decreased glucose metabolism in patients with liver cirrhosis compared to patients with liver fibrosis corresponds to reports that cirrhotic liver tissue has a depleted glycogen storage [58]. Furthermore, collagen accumulation in liver fibrosis may be associated with reduced uptake of glucose into the liver tissue [59], as observed here. GLUT-4 transporters were detected in sinusoidal endothelial cells as well as in stellate cells where they can mediate glucose uptake by semi-carbazide-sensitive amine oxidase [60] and may contribute to the fibrogenesis in patients with chronic liver diseases. This might contribute to the increased FDG uptake of active fibrosis (F2). In contrast, the expression level of GLUT-4 was found to be decreased in liver cirrhosis [61]; these findings are in line with our data, showing a significantly decreased FDG uptake for patients with METAVIR score F4 in comparison to F2.

These changes in glucose metabolism were solely related to the liver as we can confirm by our observations. In contrast, the skeletal muscle showed no significant difference in glucose metabolism for patients with and without liver fibrosis/cirrhosis.

In direct comparison, quantitative measurements by $\mathrm{TBR}_{\mathrm{Liver}}$ showed similar findings as LBR. However, the variance in the analyzed subgroups was lower for LBR, resulting in a significant difference in the pairwise comparison of F0, F1, F2, and F3, as well as a trend towards significance between F3 and F4.

There is growing evidence that time-dependent measurements of tumor tissue lead to more exact estimations of metabolic rates of glucose than conventional SUV quantification $[62,63]$. While TBR displays the ratio at the time point of acquisition, LBR is computed as the ratio of $S U V_{\text {Liver }}$ and $S U V_{\text {Blood }}$ with a scan time correction to a reference time (75 min), which accounts for the time-dependent blood SUV, but presently does not try to account for a possible time 
dependence of the liver SUV in the considered time window.

In most cells, the metabolism of ${ }^{18} \mathrm{~F}$-FDG stops after phosphorylation to ${ }^{18}$ F-FDG-6-phosphate, i.e., irreversible kinetics. Therefore, the modeling of the ${ }^{18} \mathrm{~F}$-FDG kinetics usually contains three rate constants $\mathrm{k} 1, \mathrm{k} 2$, and $\mathrm{k} 3$, whereas hepatocytes contain glucose-6-phosphatase capable of dephosphorylating ${ }^{18} \mathrm{FDG}$-6-phosphate resulting in reversible kinetics with non-negligible k4 [23]. Kinetics of ${ }^{18} \mathrm{~F}$-FDG in liver parenchyma is mainly determined by $\mathrm{k} 1$ and $\mathrm{k} 2$, with a minor impact of $\mathrm{k} 3$ and $\mathrm{k} 4$ in short-term studies lasting about 60 to 90 min post-FDG injection [31, 64]. In line with the glucose kinetics, $S_{U V}$ Liver in normal liver parenchyma varies little between 60 and $120 \mathrm{~min}$ post-injection $[65,66]$, while the blood activity slowly decreases with time in a hyperbolic manner, i.e., proportional to $1 / \mathrm{T}^{\wedge} 0.313$ ) [20].

However, one must note that the kinetics of fibrotic/cirrhotic tissue is not yet fully understood; a dynamic acquisition at different time points could reveal the actual time dependence of FDG uptake in fibrotic liver parenchyma. Due to the high methodological effort, such an analysis is reserved for a prospective study. In our retrospective study using clinical routine data, PET measurements were only available from static PET scans. With the scan time correction used here, significant disadvantages of conventional SUV quantification, such as cross-calibration errors and time dependence of the FDG distribution, are partially overcome.

Our study has some further limitations. First, the number of patients included in this study was limited, especially for the different small subgroups of liver fibrosis and cirrhosis. We used distribution-free statistical tests to account for this drawback. Second, the accepted time span of 6 months between ${ }^{18} \mathrm{~F}$-FDG PET/CT and liver biopsy may be considered rather long. However, as liver fibrosis advances rather slowly, the time span should be tolerable. In prospective studies, a shorter time span would be appreciated. Another limitation might be the sampling error of the liver biopsy: histopathological samples were received from distinct liver areas which might not represent the overall hepatic status.

\section{Conclusion}

In conclusion, we were able to show different activity levels of hepatic glucose metabolism during the process of liver fibrosis and cirrhosis as demonstrated by ${ }^{18} \mathrm{~F}$-FDG uptake with PET/CT imaging. These findings highlight the potential of noninvasive molecular imaging for estimating progression and activity of liver fibrosis.

\section{Abbreviations}

CT: Computed tomography; EVG: Elastica van Gieson; FDG: F-fluoro-deoxy-Dglucose; HE: Hematoxylin-eosin; LBR: Liver-to-blood ratio; MRI: Magnetic resonance imaging; NASH: Non-alcoholic steatohepatitis; OSEM: Ordered subsets expectation maximization; PET: Positron emission tomography; SD: Standard deviation; SUR: Standard uptake ratio; SUV: Standardized uptake value; TBR: Tissue-to-blood ratio; US: Ultrasonography; VOI: Volume of interest

\section{Acknowledgements}

Not applicable.

Funding

The authors or authors' institutions received no specific funding for this work.

\section{Availability of data and materials}

The data that support the findings of this study are available within the article.

\section{Authors' contributions}

NV and IE performed the literature search, collected and interpreted the data, and drafted the manuscript. KU and ME participated in the study design, collected the data, and edited the manuscript. KM, SB, CS, and PW helped with the literature search and acquisition and interpretation of the data. $\mathrm{FH}$ and $\mathrm{JH}$ revised the manuscript critically for important intellectual content and made substantial contributions to the data analysis. DH and JG participated in the study design and coordination and helped draft the manuscript. All authors read and approved the final manuscript.

\section{Ethics approval and consent to participate}

Approval from the local institutional review board of the University Hospital Regensburg was obtained for this retrospective study. All procedures performed in studies involving human participants were in accordance with the ethical standards of the institutional and/or national research committee and with the 1964 Helsinki Declaration and its later amendments or comparable ethical standards. Informed consent was obtained from all individual participants included in the study.

Consent for publication

Not applicable.

\section{Competing interests}

The authors declare that they have no competing interests.

\section{Publisher's Note}

Springer Nature remains neutral with regard to jurisdictional claims in published maps and institutional affiliations.

\section{Author details}

${ }^{1}$ Department of Nuclear Medicine, University Hospital Regensburg, Regensburg, Germany. ${ }^{2}$ Department of Radiology, University Hospital Regensburg, Regensburg, Germany. ${ }^{3}$ Department of Pathology, University Regensburg, Regensburg, Germany. ${ }^{4}$ Department of Surgery, University Hospital Regensburg, Regensburg, Germany. ${ }^{5} \mathrm{Helmholtz-Zentrum}$ Dresden-Rossendorf, PET Center, Institute of Radiopharmaceutical Cancer Research, Dresden, Germany. ${ }^{6}$ Department of Radiology and Nuclear Medicine, Hospital Braunschweig, Braunschweig, Germany.

Received: 15 August 2018 Accepted: 29 October 2018

Published online: 09 November 2018

References

1. Agency for Healthcare Research and Quality. Healthcare Cost and Utilization Project online Database In: www.hcup-us.ahrq.gov/home.jsp. Accessed 13 June 2018. editor. Rockville, MD.

2. Charlton M. Nonalcoholic fatty liver disease: a review of current understanding and future impact. Clin Gastroenterol Hepatol. 2004;2: 1048-58.

3. Statistisches-Bundesamt. Diagnosedaten der Krankenhäuser ab 2000. Zweigstelle Bonn. http://www.gbe-bund.de. Accessed 13 June 2018.

4. Hansen L, Sasaki A, Zucker B. End-stage liver disease: challenges and practice implications. Nurs Clin N Am. 2010;45:411-26. https://doi.org/10. 1016/j.cnur.2010.03.005.

5. Cassinotto C, Lapuyade B, Ait-Ali A, Vergniol J, Gaye D, Foucher J, et al. Liver fibrosis: noninvasive assessment with acoustic radiation force impulse elastography--comparison with FibroScan $\mathrm{M}$ and $\mathrm{XL}$ probes and FibroTest in 
patients with chronic liver disease. Radiology. 2013;269:283-92. https://doi. org/10.1148/radiol.13122208.

6. Bohte AE, de Niet A, Jansen L, Bipat S, Nederveen AJ, Verheij J, et al. Non-invasive evaluation of liver fibrosis: a comparison of ultrasoundbased transient elastography and MR elastography in patients with viral hepatitis B and C. Eur Radiol. 2014;24:638-48. https://doi.org/10.1007/ s00330-013-3046-0.

7. Tamada T, Ito K, Higaki A, Yoshida K, Kanki A, Sato T, et al. Gd-EOB-DTPAenhanced MR imaging: evaluation of hepatic enhancement effects in normal and cirrhotic livers. Eur J Radiol. 2011;80:e311-6. https://doi.org/10. 1016/j.jrad.2011.01.020.

8. Verloh N, Haimerl M, Zeman F, Schlabeck M, Barreiros A, Loss M, et al. Assessing liver function by liver enhancement during the hepatobiliary phase with Gd-EOB-DTPA-enhanced MRI at 3 tesla. Eur Radiol. 2014;24: 1013-9. https://doi.org/10.1007/s00330-014-3108-y.

9. Motosugi U, Ichikawa T, Sou H, Sano K, Tominaga L, Kitamura T, et al. Liver parenchymal enhancement of hepatocyte-phase images in Gd-EOB-DTPAenhanced MR imaging: which biological markers of the liver function affect the enhancement? J Magn Reson Imaging. 2009;30:1042-6. https://doi.org/ 10.1002/jmri.21956.

10. de Graaf W, Bennink RJ, Vetelainen R, van Gulik TM. Nuclear imaging techniques for the assessment of hepatic function in liver surgery and transplantation. J Nucl Med. 2010;51:742-52. https://doi.org/10.2967/ jnumed.109.069435.

11. Yoshida M, Shiraishi S, Sakaguchi F, Utsunomiya D, Tashiro K, Tomiguchi S, et al. A quantitative index measured on (9)(9)mTc GSA SPECT/CT 3D fused images to evaluate severe fibrosis in patients with chronic liver disease. Jpn J Radiol. 2012;30:435-41. https://doi.org/10.1007/s11604-012-0072-9.

12. Onodera Y, Takahashi K, Togashi T, Sugai Y, Tamaki N, Miyasaka K. Clinical assessment of hepatic functional reserve using 99mTc DTPA galactosyl human serum albumin SPECT to prognosticate chronic hepatic diseases-validation of the use of SPECT and a new indicator. Ann Nucl Med. 2003;17: $181-8$.

13. Kaibori M, Ha-Kawa SK, Maehara M, Ishizaki M, Matsui K, Sawada S, et al. Usefulness of Tc-99m-GSA scintigraphy for liver surgery. Ann Nucl Med. 2011;25:593-602. https://doi.org/10.1007/s12149-011-0520-0.

14. Wang H, Feng M, Frey KA, Ten Haken RK, Lawrence TS, Cao Y. Predictive models for regional hepatic function based on 99mTc-IDA SPECT and local radiation dose for physiologic adaptive radiation therapy. Int J Radiat Oncol Biol Phys. 2013;86:1000-6. https://doi.org/10.1016/j.jprobp.2013.04.007.

15. Alavi A, Kung JW, Zhuang H. Implications of PET based molecular imaging on the current and future practice of medicine. Semin Nucl Med. 2004;34:56-69.

16. Musiek ES, Chen Y, Korczykowski M, Saboury B, Martinez PM, Reddin JS, et al. Direct comparison of FDG-PET and ASL-MRI in Alzheimer's disease. Alzheimer's Dement. 2012;8:51-9. https://doi.org/10.1016/j.jalz.2011.06.003.

17. Ewers M, Insel PS, Stern Y, Weiner MW. Cognitive reserve associated with FDG-PET in preclinical Alzheimer disease. Neurology. 2013;80:1194-201. https://doi.org/10.1212/WNL.0b013e31828970c2.

18. Buvat I. Quantification in emission tomography: challenges, solutions, and performance. Nucl Inst Methods Phys Res A. 2007;571:10-3.

19. van den Hoff J, Hofheinz F, Oehme L, Schramm G, Langner J, BeuthienBaumann B, et al. Dual time point based quantification of metabolic uptake rates in (18)F-FDG PET. EJNMMI Res. 2013;3:16. https://doi.org/10. 1186/2191-219X-3-16.

20. van den Hoff J, Lougovski A, Schramm G, Maus J, Oehme L, Petr J, et al. Correction of scan time dependence of standard uptake values in oncological PET. EJNMMI Res. 2014;4:18. https://doi.org/10.1186/2191219X-4-18.

21. Hofheinz F, Bütof R, Apostolova I, Zöphel K, Steffen IG, Amthauer H, et al. An investigation of the relation between tumor-to-liver ratio (TLR) and tumor-to-blood standard uptake ratio (SUR) in oncological FDG PET. EJNMMI Res. 2016;6:19. https://doi.org/10.1186/s13550-016-0174-y.

22. Brix G, Ziegler Sl, Bellemann ME, Doll J, Schosser R, Lucht R, et al. Quantification of [(18)F]FDG uptake in the normal liver using dynamic PET: impact and modeling of the dual hepatic blood supply. J Nucl Med. 2001; 42:1265-73.

23. Keiding S. Bringing physiology into PET of the liver. J Nucl Med. 2012:53: 425-33. https://doi.org/10.2967/jnumed.111.100214.

24. Tragardh M, Moller N, Sorensen M. Methodologic considerations for quantitative 18F-FDG PET/CT studies of hepatic glucose metabolism in healthy subjects. J Nucl Med. 2015;56:1366-71. https://doi.org/10.2967/ jnumed.115.154211.

25. Hernandez-Martinez A, Marin-Oyaga VA, Salavati A, Saboury B, Codreanu I, Lam MG, et al. Quantitative assessment of global hepatic glycolysis in patients with cirrhosis and normal controls using 18F-FDG-PET/CT: a pilot study. Ann Nucl Med. 2014;28:53-9. https://doi.org/10.1007/s12149013-0780-y.

26. Bural GG, Torigian DA, Burke A, Houseni M, Alkhawaldeh K, Cucchiara A, et al. Quantitative assessment of the hepatic metabolic volume product in patients with diffuse hepatic steatosis and normal controls through use of FDG-PET and MR imaging: a novel concept. Mol Imaging Biol. 2010;12:2339. https://doi.org/10.1007/s11307-009-0258-4.

27. Abele JT, Fung $\mathrm{Cl}$. Effect of hepatic steatosis on liver FDG uptake measured in mean standard uptake values. Radiology. 2010;254:917-24. https://doi. org/10.1148/radiol.09090768.

28. Dostbil Z, Varoglu E, Serdengecti M, Kaya B, Onder H, Sari O. Evaluation of hepatic metabolic activity in non-alcoholic fatty livers on 18FDG PET/CT. Rev Esp Med Nucl Imagen Mol. 2013;32:156-61. https://doi.org/10.1016/j. remn.2012.04.006.

29. Kuker RA, Mesoloras G, Gulec SA. Optimization of FDG-PET/CT imaging protocol for evaluation of patients with primary and metastatic liver disease. Int Semin Surg Oncol. 2007;4(17). https://doi.org/10.1186/1477-7800-4-17.

30. Lin CY, Ding HJ, Lin CC, Chen CC, Sun SS, Kao CH. Impact of age on FDG uptake in the liver on PET scan. Clin Imaging. 2010;34:348-50. https://doi. org/10.1016/j.clinimag.2009.11.003.

31. Wang G, Corwin MT, Olson KA, Badawi RD, Sarkar S. Dynamic PET of human liver inflammation: impact of kinetic modeling with optimization-derived dual-blood input function. Phys Med Biol. 2018. https://doi.org/10.1088/ 1361-6560/aac8cb.

32. Bedossa P, Poynard T. An algorithm for the grading of activity in chronic hepatitis C. The METAVIR Cooperative Study Group. Hepatology. 1996;24: 289-93. https://doi.org/10.1002/hep.510240201.

33. Poynard T, Bedossa P, Opolon P. Natural history of liver fibrosis progression in patients with chronic hepatitis C. Lancet. 1997;349:825-32. https://doi. org/10.1016/50140-6736(96)07642-8.

34. Ishak K, Baptista A, Bianchi L, Callea F, De Groote J, Gudat F, et al. Histological grading and staging of chronic hepatitis. J Hepatol. 1995;22:696-9.

35. Schuppan D, Afdhal NH. Liver cirrhosis. Lancet. 2008;371:838-51. https://doi. org/10.1016/50140-6736(08)60383-9.

36. Udell JA, Wang CS, Tinmouth J, FitzGerald JM, Ayas NT, Simel DL, et al. Does this patient with liver disease have cirrhosis? JAMA. 2012;307:832-42. https://doi.org/10.1001/jama.2012.186.

37. Marcellin P, Gane E, Buti M, Afdhal N, Sievert W, Jacobson IM, et al. Regression of cirrhosis during treatment with tenofovir disoproxil fumarate for chronic hepatitis B: a 5-year open-label follow-up study. Lancet. 2013; 381:468-75. https://doi.org/10.1016/S0140-6736(12)61425-1.

38. Hui JM, Hodge A, Farrell GC, Kench JG, Kriketos A, George J. Beyond insulin resistance in NASH: TNF-alpha or adiponectin? Hepatology. 2004;40:46-54. https://doi.org/10.1002/hep.20280.

39. Browning JD, Horton JD. Molecular mediators of hepatic steatosis and liver injury. J Clin Investig. 2004;114:147-52. https://doi.org/10.1172/JC|200422422.

40. Day CP, James OF. Steatohepatitis: a tale of two "hits"? Gastroenterology. 1998;114:842-5.

41. Karim S, Adams DH, Lalor PF. Hepatic expression and cellular distribution of the glucose transporter family. World J Gastroenterol. 2012;18:6771-81. https://doi.org/10.3748/wjg.v18.i46.6771.

42. Livak KJ, Schmittgen TD. Analysis of relative gene expression data using real-time quantitative PCR and the 2(-Delta Delta C(T)) method. Methods (San Diego, Calif). 2001;25:402-8. https://doi.org/10.1006/meth.2001.1262.

43. Karim S, Liaskou E, Fear J, Garg A, Reynolds G, Claridge L, et al. Dysregulated hepatic expression of glucose transporters in chronic disease: contribution of semicarbazide-sensitive amine oxidase to hepatic glucose uptake. Am J Physiol Gastrointest Liver Physiol. 2014;307:G1180-90. https://doi.org/10. 1152/ajpgi.00377.2013.

44. Levitsky LL, Zheng Q, Mink K, Rhoads DB. GLUT-1 and GLUT-2 mRNA, protein, and glucose transporter activity in cultured fetal and adult hepatocytes. Am J Phys. 1994;267:E88-94. https://doi.org/10.1152/ajpendo. 1994.267.1.E88.

45. Bilir BM, Gong TW, Kwasiborski V, Shen CS, Fillmore CS, Berkowitz CM, et al. Novel control of the position-dependent expression of genes in hepatocytes. The GLUT-1 transporter. J Biol Chem. 1993;268:19776-84. 
46. Nanji AA, Fogt F, Griniuviene B. Alterations in glucose transporter proteins in alcoholic liver disease in the rat. Am J Pathol. 1995;146:329-34.

47. Thorens B. GLUT2, glucose sensing and glucose homeostasis. Diabetologia. 2015;58:221-32. https://doi.org/10.1007/s00125-014-3451-1.

48. Lodish H, Berk A, Zipursky SL, Matsudaira P, Baltimore D, Darnell J. Molecular cell biology 4th edition. National Center for Biotechnology Information, Bookshelf. 2000

49. Kurkijarvi R, Yegutkin GG, Gunson BK, Jalkanen S, Salmi M, Adams DH. Circulating soluble vascular adhesion protein 1 accounts for the increased serum monoamine oxidase activity in chronic liver disease. Gastroenterology. 2000;1 19:1096-103.

50. Pasarín M, Abraldes JG, Liguori E, Kok B, La Mura V. Intrahepatic vascular changes in non-alcoholic fatty liver disease: potential role of insulinresistance and endothelial dysfunction. World J Gastroenterol. 2017;23:6777.

51. Spolarics Z, Pekala PH, Bagby GJ, Spitzer JJ. Brief endotoxemia markedly increases expression of GLUT1 glucose transporter in Kupffer, hepatic endothelial and parenchymal cells. Biochem Biophys Res Commun. 1993; 193:1211-5. https://doi.org/10.1006/bbrc.1993.1754

52. Heye $T$, Yang SR, Bock M, Brost S, Weigand $K$, Longerich T, et al. MR relaxometry of the liver: significant elevation of $\mathrm{T} 1$ relaxation time in patients with liver cirrhosis. Eur Radiol. 2012;22:1224-32. https://doi.org/10. 1007/s00330-012-2378-5.

53. Katsube T, Okada M, Kumano S, Hori M, Imaoka I, Ishii K, et al. Estimation of liver function using T1 mapping on Gd-EOB-DTPA-enhanced magnetic resonance imaging. Investig Radiol. 2011;46:277-83. https://doi.org/10.1097/ RLI.0b013e318200f67d.

54. Thomsen C, Christoffersen P, Henriksen O, Juhl E. Prolonged T1 in patients with liver cirrhosis: an in vivo MRI study. Magn Reson Imaging. 1990;8:599604. https://doi.org/10.1016/0730-725X(90)90137-Q.

55. Friedman SL. Mechanisms of hepatic fibrogenesis. Gastroenterology. 2008; 134:1655-69.

56. Czaja AJ. Hepatic inflammation and progressive liver fibrosis in chronic liver disease. World J Gastroenterol: WJG. 2014;20:2515.

57. Hintermann E, Ehser J, Bayer M, Pfeilschifter JM, Christen U. Mechanism of autoimmune hepatic fibrogenesis induced by an adenovirus encoding the human liver autoantigen cytochrome P450 2D6. J Autoimmun. 2013:44:49-60.

58. Yamanaka H, Genjida K, Yokota K, Taketani Y, Morita K, Miyamoto Kl, et al. Daily pattern of energy metabolism in cirrhosis. Nutrition (Burbank, Los Angeles County, Calif). 1999;15:749-54.

59. Nielsen MF, Caumo A, Aagaard NK, Chandramouli V, Schumann WC, Landau BR, et al. Contribution of defects in glucose uptake to carbohydrate intolerance in liver cirrhosis: assessment during physiological glucose and insulin concentrations. Am J Physiol Gastrointest Liver Physiol. 2005;288:G1135-G43.

60. Weston CJ, Adams DH. Hepatic consequences of vascular adhesion protein1 expression. J Neural Transm (Vienna, Austria : 1996). 2011;118:1055-64. https://doi.org/10.1007/s00702-011-0647-0

61. Hoffler U, Hobbie K, Wilson R, Bai R, Rahman A, Malarkey D, et al. Dietinduced obesity is associated with hyperleptinemia, hyperinsulinemia, hepatic steatosis, and glomerulopathy in C57BI/6J mice. Endocrine. 2009;36: 311-25. https://doi.org/10.1007/s12020-009-9224-9.

62. Butof R, Hofheinz F, Zophel K, Stadelmann T, Schmollack J, Jentsch C, et al. Prognostic value of Pretherapeutic tumor-to-blood standardized uptake ratio in patients with esophageal carcinoma. J Nucl Med. 2015;56:1150-6. https://doi.org/10.2967/jnumed.115.155309.

63. Hofheinz F, van den Hoff J, Steffen IG, Lougovski A, Ego K, Amthauer H, et al. Comparative evaluation of SUV, tumor-to-blood standard uptake ratio (SUR), and dual time point measurements for assessment of the metabolic uptake rate in FDG PET. EJNMMI Res. 2016;6:53. https://doi.org/10.1186/ s13550-016-0208-5.

64. Bender D, Munk OL, Feng HQ, Keiding S. Metabolites of (18)F-FDG and 3-O(11)C-methylglucose in pig liver. J Nucl Med. 2001;42:1673-8.

65. Sorensen M, Mikkelsen KS, Frisch K, Bass L, Bibby BM, Keiding S. Hepatic galactose metabolism quantified in humans using 2-18F-fluoro-2-deoxy-Dgalactose PET/CT. J Nucl Med. 2011;52:1566-72. https://doi.org/10.2967/ jnumed.111.092924.

66. Szopa I, Gorczewski K, d'Amico A, Jarząb B. Is there a necessity of Standard Uptake Value correction in liver reference level? In: Dössel O, Schlegel WC, editors. World Congress on Medical Physics and Biomedical Engineering, September 7-12, 2009, Munich, Germany. Berlin: Springer Berlin Heidelberg; 2009. p. 627-9.

\section{Submit your manuscript to a SpringerOpen ${ }^{\circ}$ journal and benefit from:}

- Convenient online submission

- Rigorous peer review

- Open access: articles freely available online

High visibility within the field

- Retaining the copyright to your article

Submit your next manuscript at $\boldsymbol{s p r i n g e r o p e n . c o m ~}$ 